\title{
Factors Affecting the Autologous Mixed Lymphocyte Reaction in Kidney Transplantation
}

\author{
Laphalle Fuller, Cathy Flaa, David Jaffe, Jose Strauss, \\ George K. Kyriakides, and Joshua Miller, Division of Transplantation, \\ Departments of Surgery, Medicine, Microbiology, and Pediatrics, \\ University of Miami School of Medicine, Miami Veterans \\ Administration Hospital, Miami, Florida 33101
}

A B S T R A C T In long-term well adapted kidney transplant recipients we have found a close correlation between the $T$ helper $\left(T_{H}\right)$ : $T$ suppressor/cytotoxic $\left(T_{S / C}\right)$ subset ratios and the presence of $T$ cells that respond in the autologous mixed lymphocyte reaction (AMLR). In 21 recipients with $\mathrm{T}$ cell $\mathrm{E}$ rosette levels ranging between 53 and $86 \%$ and $\mathrm{T}_{\mathrm{H}}: \mathrm{T}^{\mathrm{S} / \mathrm{C}}$ ratios between 0.15 to 2.10 , ratios of $>0.8$ correlated with AMLR responses (13/13), and ratios of $<0.8$ with AMLR nonreactivity (7/7). By contrast, the allogeneic MLR showed no apparent correlation with the $T_{H}: T_{S / C}$ ratios or with the AMLR pre- or postoperatively. It was found that the AMLR in 22 of 23 normal individuals was markedly inhibited by autologous $T$ cells obtained from peripheral blood lymphocytes, exposed to 3,000 $\mathrm{rad}(\mathrm{Tx})$ and added as a third component to the cultures. In contrast, 13 of 13 kidney transplant recipients failed to exhibit this Tx AMLR inhibitory cell population. The "naturally occurring" $T$ inhibitory cells, fractionated by an affinity column chromatography procedure into $x$-irradiated $T_{H}$ and $T_{S / C}$ subsets, inhibited the AMLR to the same extent as unseparated $T x$ cells. In cell interchange studies performed in four of five HLA identical donor-recipient pairs the Tx cells of the (normal) donor inhibited the recipient AMLR (immunosuppressed), but recipient $T_{x}$ cells failed to inhibit the donor AMLR. Finally $T$ cells, primed in AMLR and allogeneic MLR for $10 \mathrm{~d}$ were tested for AMLR or allogeneic MLR inhibitory activity. Allogeneic MLR primed $x$-irradiated cells, inhibited both the AMLR and allogeneic MLR while AMLR x-irradiated primed cells inhibited neither reaction. The Tx AMLR inhib-

Received for publication 12 August 1982 and in revised form 29 November 1982. itor found in normal peripheral blood, appears to be a cell that is highly sensitive to the effects of biologic or pharmacologic immunosuppressive agents.

\section{INTRODUCTION}

The autologous mixed lymphocyte reaction (AMLR) ${ }^{1}$ has been thought to reflect an autoregulatory mechanism of immunity $(1,2)$. The AMLR is highly sensitive to effects that alter normal immune homeostasis such as physiologic doses of corticosteroids (3) and autoimmune disease states $(4,5)$. The reaction appears to be activated by a stimulating population of non-T cells fractionated from peripheral blood lymphocytes (PBL) (1) with a comparably small subset of $\mathrm{T}$ helper cells playing a major role in the response (6). Both primary and secondary responses with kinetics similar to, but with less magnitude than, the allogeneic MLR have been described (7), and cytotoxic cells have also been generated (8). Although the responding cells in the AMLR have been reported for the most part to be mutually exclusive of those responding in the allogeneic MLR (9), the antigens that stimulate the AMLR may or may not have a relation to lymphocyte defined (LD) antigens $(7,10)$. Because of exquisite sensitivity of the AMLR to alteration of immune status in the human subject we embarked on a study of the factors that affect the reaction following renal transplantation.

\footnotetext{
${ }^{1}$ Abbreviations used in this paper: AMLR, autologous mixed lymphocyte reaction; D, donor of kidney; ERFC, E rosette-forming cells; FCS, fetal calf serum; MLR, allogeneic mixed lymphocyte reaction; NT, non-T cells; PBL, peripheral blood lymphocytes; $R$, recipient of kidney; $T_{H}$, $T$ helper cells; $T_{\mathrm{s} / \mathrm{c}}, \mathrm{T}$ suppressor/cytotoxic cells; $\mathrm{x}$, gamma-irradiated lymphocytes.
} 
In the present report we describe changes in the AMLR occurring after renal transplantation that directly relate to the $T$ helper $\left(T_{H}\right)$ to $T$ suppressor/cytotoxic $\left(\mathrm{T}_{\mathrm{S} / \mathrm{C}}\right)$ cell ratio found in PBL. We also describe the inhibitory effects of $x$-irradiated $T$ cells $(T x)$, isolated from peripheral blood and added as a third component to the AMLR, in normal individuals and in patients with end-stage renal disease before immunosuppressive therapy. Attempts were made to further purify the Tx inhibitory cell of the AMLR and $T_{11}$ and $\mathrm{T}_{\mathrm{S} / \mathrm{c}}$ : subsets by a cellular affinity column technique (11). We also asked whether the Tx AMLR inhibitor cells that were isolated from putatively quiescent PBL could be differentiated from the primed $\mathrm{T}$ suppressor cells that were generated in allogeneic MLR as we have previously described (12), or from primed cells derived from the AMLR itself. Finally, we looked for this AMLR inhibitory $T$ cell in transplant recipients undergoing immunosuppressive therapy and in a patient with an "autoimmune" disease state, and compared the effects of interchanging cellular elements between several genotyped HLA identical donor-recipient sibling pairs as a control for the disease and immunosuppressed state.

\section{METHODS}

Patients. The study subjects were pairs of living related donors and their corresponding transplant recipients or recipients of cadaveric kidneys (members of a pair designated as " $R$ " for recipient and " $D$ " for donor). Other subjects were "normal" unrelated volunteer blood donors, designated as "I", chosen to be two HLA DR antigen mismatches with R. The immunosuppressive therapy for the renal transplant recipients consisted of (1) azathioprine or cyclophosphamide and methylprednisolone (Medrol, Upjohn Co., Kalamazoo, MI) as a long-term regimen, with antilymphocyte globulin administered intravenously for 2 wk after transplantation, or (2) cyclosporin A and Medrol as long-term therapy in selected patients. The AMLR assays were performed on "normal" laboratory volunteers, on patients treated for end stage renal disease by hemodialysis before transplantation and on transplant recipients. Some of the study subjects were tested while being treated with immunosuppression before transplantation because of their original disease.

Cell preparation. Peripheral blood mononuclear cells were collected from whole blood using Ficoll-Hypaque density gradients. The cell concentrations were adjusted to $5 \times 10^{6} / \mathrm{ml}$ in RPMI 1640 , supplemented with $20 \%$ fetal calf serum (FCS) (Gibco Laboratories, Grand Island, NY), and mixed with an equal volume of $1 \%$ sheep erythrocytes (E) that had been treated with aminoethylthioronium bromide. The $\mathrm{E}$ rosette forming cells (ERFC) were layered onto a chilled Ficoll-Hypaque gradient. After $2 \mathrm{~h}$ at $4^{\circ} \mathrm{C}$, the tubes were centrifuged $(600 \mathrm{~g})$. Non-T lymphocytes (NT) were obtained from the interface and the rosetted $T$ lymphocytes in the pellet were treated with distilled water to lyse the erythrocytes. Both factions, i.e., NT and T, were washed in media and then adjusted to a concentration of $1 \times 10^{6} / \mathrm{ml}$ in RPMI 1640 supplemented with L-glutamine, penicillin- streptomycin, and 7\% filtered heat-inactivated "normal" human serum (complete medium).

Isolation of T cell subpopulations. Two separate cellular affinity column chromatography procedures (I and II, Fig. 1) were used with mouse anti-human $T$ cell subset monoclonal antibodies OKT8 (Ortho Pharmaceutical, Raritan, $\mathrm{NJ}$ ), and biotin conjugated anti-Leu 3a (Becton-Dickinson Co., Sunnyvale, CA). The T cells obtained by $\mathrm{E}$ rosetting and Ficoll-Hypaque density gradients were treated in procedure I with $5 \mu \mathrm{l}$ of OKT8 and in procedure II with $5 \mu \mathrm{l}$ of biotin conjugated anti-leucine (Leu) $3 \mathrm{a}$ per $1 \times 10^{6} \mathrm{~T}$ cells. The cell suspensions were allowed to stand for $20 \mathrm{~min}$ at room temperature with gentle agitation. In procedure I, protein A-Sepharose 6 MB (Pharmacia Fine Chemicals, Inc., Piscataway, $\mathrm{NJ}$ ) was washed according to manufacturer's recommendation, suspended in RPMI 1640 containing 5\% FCS, and packed into a sterile $12-\mathrm{cm}$ column (Pharmacia C 10/20). In procedure II, an Avidin (Sigma Chemical Co., St. Louis, MO) Sepharose $6 \mathrm{MB}$ column was prepared by coupling Avidin (10 mg) dissolved in $5 \mathrm{ml}$ of $0.1 \mathrm{M} \mathrm{NaHCO}$ and $0.5 \mathrm{M} \mathrm{NaCl}$, washing and processing as described in the Pharmacia booklet. The coupled washed gel was suspended in minimal essential medium containing 5\% FCS and packed in a column as noted above. Before use, the gels I and II were $\mathrm{x}$-irradiated with 50,000 rad from a Cobalt 60 source (Atomic Energy of Canada, Ltd., Ottawa, Canada) to insure sterility. The monoclonal antibody-treated cells I and II were applied to their respective columns (i.e., I to protein A Sepharose $6 \mathrm{MB}$ and II to Avidin Sepharose $6 \mathrm{MB}$ ), $50 \times 10^{6}$ cells per column $(\sim 9.4 \mathrm{ml})$, for $5 \mathrm{~min}$. The $T_{H}$ cells were eluted from column I with RPMI 1640 plus 5\% FCS in a resulting concentration of $>95 \%$, with $<0.5 \%$ being $\mathrm{T}_{\mathrm{S} / \mathrm{C}}$ cells. (The starting material $\mathrm{T}_{\mathrm{H}}$ concentration was $\sim 55 \%$ ).

ISOLATION OF T CELL SUBPOPULATION



Figure 1 Isolation of $T_{11}$ and $T_{S / C}$ cell subpopulations by cellular affinity column chromatography. The viability of eluted cells was determined by trypan blue exclusion $(>90 \%)$. The percent cell concentration was quantitated by direct immunofluorescence counting employing anti-Leu $2 a$ and anti-Leu 3a FITC conjugated anti-T cell subset antibodies. 
The $\mathrm{T}_{\mathrm{S} / \mathrm{C}}$ concentration of the cells eluted from column II was also increased to $>95 \%$ with $<0.5 \%$ contamination with $\mathbf{T}_{\mathrm{H}}$ cells (the starting material $\mathbf{T}_{\mathrm{S} / \mathrm{C}}$ concentration was $\sim 20 \%$ ).

Enumeration of $T$ cell subsets by immunofluorescence. Mouse monoclonal IgG antibodies specific for human peripheral $\mathrm{T}$ lymphocyte subsets anti-human Leu 2a (cytotoxic/suppressor) and anti-human Leu 3a (helper/inducer) both fluorescein conjugated, were used in direct immunofluorescent counting of $T_{H}$ and $T_{S / C}$ cell subsets, or Orthoclone monoclonal antibodies OKT4 $\left(\mathrm{T}_{\mathrm{H}}\right)$ and OKT8 $\left(\mathrm{T}_{\mathrm{S} / \mathrm{C}}\right)$ were used in indirect immunofluorescence assays using FITC conjugated goat anti-human IgG as the second antibody (13). One million cells were incubated with $5 \mu \mathrm{l}$ of the appropriate undiluted monoclonal reagent for $45 \mathrm{~min}$ on ice. The cell preparations were washed twice in RPMI 1640 containing $25 \mathrm{mM}$ Hepes buffer and 5\% heat-inactivated FCS, and were visually analyzed for fluorescence with a fluorescence microscope equipped with epillumination. Three counts of at least 200 cells were performed on each sample. Results were expressed as a mean percent of total ERFC cells and as the ratio of $T_{H}: T_{S / C}$.

Autologous and allogeneic mixed lymphocyte reactions. Assays were performed in triplicate in microtiter plates using $1 \times 10^{5}$ responding cells mixed with $1 \times 10^{5} \mathrm{x}$-irradiated $(1,500 \mathrm{rad})$ stimulating cells in a total volume of $0.2 \mathrm{ml}$ of complete medium. Cultures were incubated for $3,5,7$, and $9 \mathrm{~d}$ at $37^{\circ} \mathrm{C}$ in a humidified $7 \% \mathrm{CO}_{2}$ atmosphere and then pulsed with $1 \mu \mathrm{C}$ of methyl- $\left[{ }^{3} \mathrm{H}\right]$ thymidine for $18 \mathrm{~h}$. The cultures were processed on a multiple automated sample harvester (Mash II, Microbiological Associates, Walkersville MD) (14). The incorporation of $\left[{ }^{3} \mathrm{H}\right]$ thymidine was measured in a liquid scintillation counter (Packard Instruments, Inc. Downers Grove, IL) and reported as mean counts per minute with $<10 \%$ total variation among triplicates.

Generation of primed $T$ cells. In a procedure similar to one we have previously described (15) macrocultures of 1.2 $\times 10^{6}$ responding cells and $0.6 \times 10^{6}$ stimulating cells of the allogeneic MLR $(\mathrm{A}+\mathrm{Ix})$ or the same number of T-cells stimulated with autologous NT cells in the AMLR, $(\mathrm{T}+\mathrm{NTx})$, were prepared in $2.0 \mathrm{ml}$ vol of RPMI $1640 \mathrm{sup}-$ plemented with L-glutamine, amphicillin, and $7 \%$ heat-inactivated fresh human serum and incubated for $9 \mathrm{~d}$ in a humidified atmosphere of $7 \% \mathrm{CO}_{2}$. Several macrocultures were then aseptically pooled, washed three times with fresh unsupplemented medium, and the viability was determined These primed cells were designated as $A^{\prime} I$ or $T^{\prime} N T$. As an additional step the $A^{\prime} I$ cells were adjusted to $5 \times 10^{6} / \mathrm{ml}$ in RPMI 1640 supplemented with $20 \%$ FCS and mixed with an equal volume of $1 \%$ sheep erythrocytes that had been treated with aminoethylthioronium bromide (16) to isolate ERFC $T$ cells as described above. This procedure enriched the $A^{\prime} I$ cells to $>90 \% \mathrm{~T}$ cells $\left(\mathrm{A}^{\prime} \mathrm{IT}\right)$. The $\mathrm{T}^{\prime} \mathrm{NT}$ population was already shown to be maximally enriched to $>90 \% \mathrm{~T}$ cells at $9 \mathrm{~d}$ in culture. The two cell populations $\mathrm{A}^{\prime} \mathrm{IT}$ and $\mathrm{T}^{\prime} \mathrm{NT}$ were adjusted to a concentration of $1 \times 10^{6} / \mathrm{ml}$ for use in the suppressor cell assay similar to one we have previously described (12).

Suppressor cell assay. Cultures for both the allogeneic MLR and AMLR were prepared in microtiter plates containing $1 \times 10^{5}$ each of responder and $x$-irradiated stimulator cells in $0.2 \mathrm{ml}$ of complete medium. The putative suppressor cell suspensions $\left(1 \times 10^{5}\right.$ cells in $\left.0.1 \mathrm{ml}\right)$ were $x$-irradiated with 3,000 rad and added as a third component to the cultures. The plates were incubated in a humidified atmosphere of $7 \% \mathrm{CO}_{2}$ for $3,5,7$, and $9 \mathrm{~d}$ and pulse-labeled with $1 \mu \mathrm{Ci}$ of $\left[{ }^{3} \mathrm{H}\right]$ thymidine $18 \mathrm{~h}$ before processing for liquid scintillation.

\section{RESULTS}

Correlation between AMLR and T-helper:T-suppressor/cytotoxic ratio in kidney transplant recipients. Over 60 patients have been sequentially followed between 6 mo and 3 yr postoperatively, in the absence of rejection episodes and with normal renal function after transplantation, by serial monitoring of $T$ cell subsets using anti- $T_{H}$ and $T_{S / C}$ monoclonal antibodies and immunofluorescent cell counting $(17,18)$. We have found that changes to severe inversion of the $T_{H}: T_{S / C}$ ratios have been associated with a propensity towards opportunistic infections despite normal E rosette T cell counts of PBL (19). We asked whether there was a relationship between the presence of depressed $T_{H}: T_{S / C}$ ratios in PBL and the presence or absence of the AMLR. In Table I studies in 21 transplant patients are shown. 4 of these were recipients of transplants from HLA identical living related donors, 11 were from haploidentical living related donors, and 6 were from cadaver donors. All but two exhibited "normal" ERFC levels. However, the ratios of $T_{H}: T_{S / C}$ ranged from 0.15 to 2.10 . The normal mean $T_{H}: T_{S / C}$ ratios using PBL of 23 "normal" volunteers in this laboratory was $1.84 \pm 0.21$. The mean counts per minute $\left[{ }^{3} \mathrm{H}\right]$ thymidine uptake of the AMLR (RT + RNTx), allogeneic MLR (RT + Ix), and of control cultures (RT $+\mathrm{RTx})$ are shown. We have defined a positive AMLR as a response in which the $9-\mathrm{d}$ peak $\left[{ }^{3} \mathrm{H}\right]$ thymidine uptake of the experimental T + NTx was at least 1,000 $\mathrm{cpm}$, and greater than three times the value of the control $\mathrm{T}+\mathrm{Tx}$. Using this criterion $8 / 8$ patients with $\mathrm{T}_{\mathrm{H}}: \mathrm{T}_{\mathrm{S} / \mathrm{C}}$ ratios of $<0.8 \mathrm{had}$ a negative AMLR and 13/ 13 patients with $T_{H}: T_{S / C}$ ratios of $>0.8$ had a positive AMLR. This was despite a significant difference in the dose of immunosuppression used between the two groups that might have led to the expectation of the opposite result, i.e., the mean dosage of Medrol was $0.19 \pm 0.009(\mathrm{SE}) \mathrm{mg} / \mathrm{kg}$ in the nonreactor group vs. $0.29 \pm 0.009$ (SE) $\mathrm{mg} / \mathrm{kg}$ in AMLR responders $(P<0.01)(20)$, reflecting the individual sensitivity to immunosuppression indicated by both the AMLR and $T$ cell subset ratios. By contrast, in 20 of the 21 recipients (including 7 of 8 AMLR nonreactors) the allogeneic MLR was relatively normal and showed no apparent correlation with the $T$ cell subset ratios. Seven of eight patients studied before transplantation on maintenance hemodialysis were AMLR reactors (data not shown). The magnitude of the response in general was somewhat decreased, and less than that in many 
TABLE I

Correlation of Helper:Suppressor T Cell Phenotypes and the AMLR in Kidney Transplant Patients ${ }^{\circ}$

\begin{tabular}{|c|c|c|c|c|c|c|c|c|c|c|}
\hline \multirow[b]{2}{*}{ Match } & \multirow[b]{2}{*}{ No. } & \multicolumn{2}{|c|}{ Daily immunosuppressive dose } & \multicolumn{4}{|c|}{ \%T cells } & \multicolumn{3}{|c|}{ cpm $9 \mathrm{~d}$ culture } \\
\hline & & Azathioprine & Medrol & ERFC & $T_{H}$ & $T_{s / C}$ & $T_{H}: T_{S / C}$ & $R T+R T x$ & $\mathrm{RT}+\mathrm{RNT} x$ & $R T+1 \times t$ \\
\hline & & $m g / k g$ & $m g / k g$ & & & & & & & \\
\hline Haplo-Id. LRD & 4 & $1.12 \pm 0.9 \S$ & $0.21 \pm 0.05$ & $76 \pm 3^{\prime \prime}$ & $18 \pm 4^{\prime \prime}$ & $54 \pm 4^{\| !}$ & $0.15-0.50^{\|}$ & $294 \pm 108$ & $521 \pm 105$ & $18,587 \pm 8,285$ \\
\hline HLA-Id. LRD & 2 & $0.85 \pm 0.5$ & $0.14 \pm 0.4$ & $84 \pm 0$ & $22 \pm 8$ & $65 \pm 8$ & $0.19-0.53$ & 264,382 & 106,124 & $17,925,18,808$ \\
\hline Cadaver & 2 & $0.85 \pi$ & $0.19 \pm 0.07$ & $44 \pm 2$ & $17 \pm 3$ & $22 \pm 3$ & $0.70-0.74$ & 180,395 & 149,824 & $5,439,49,832$ \\
\hline Mean \pm SE & & & $0.19 \pm 0.009^{\circ}$ & & & & $\mathrm{T}_{11}: \mathrm{T}_{\mathrm{S} / \mathrm{C}}<0.8^{\circ}$ & & & \\
\hline Haplo-Id. LRD & 7 & $1.95 \pm 0.1$ & $0.34 \pm 0.04$ & $80 \pm 1$ & $45 \pm 3$ & $37 \pm 3$ & $0.82-2.11$ & $442 \pm 97$ & $16,706 \pm 1,064$ & $30,947 \pm 6,487$ \\
\hline HLA-Id. LRD & 2 & $1.09 \S$ & $0.26 \pm 0.15$ & $77 \pm 1$ & $42 \pm 8$ & $40 \pm 8$ & $0.86-1.28$ & 272,547 & $1,398,3,100$ & $31,645-39,820$ \\
\hline Cadaver & 4 & $0.95 \pi$ & $0.24 \pm 0.06$ & $64 \pm 1$ & $40 \pm 6$ & $32 \pm 4$ & $1.08-1.57$ & $261 \pm 130$ & $9,565 \pm 4,630$ & $18,927 \pm 8,991$ \\
\hline Mean $\pm S E$ & & & $0.29 \pm 0.009 \rrbracket$ & & & & $\mathrm{T}_{\mathrm{H}}: \mathrm{T}_{\mathrm{S} / \mathrm{C}}>0.81 \downarrow$ & & & \\
\hline
\end{tabular}

- The AMLR response is considered positive when the 9-d cpm of the mean of the triplicate experimental (RT + RNTx) cultures is $>1,000 \mathrm{cpm}$ and at least three times that of the control (RT + RTx) cultures. Values in this table are expressed as mean $\pm \mathrm{SE}$, including drug dosage. Exceptions: _- indicates range; † Selected to be two HLA DR antigen mismatches with $R$.

\$ One patient in this group was treated with cyclophosphamide in place of azathioprine.

"Although these tests were performed using the same blood sample as the AMLR and allogeneic MLR, there was a variance of $<10 \%$ over at least three monthly intervals for each patient during the study. Also, the percent $T_{H}: T_{\mathrm{S} / \mathrm{C}}$ do not equal the total $\mathrm{E}$ rosetting cells and occasionally are in excess of this number.

I Azathioprine dosage in one patient. The others in this group were treated with cyclosporin $\mathrm{A}$.

- Mean daily dosage of Medrol \pm SE over several weeks without alteration. Other immunosuppressive drug dosage also did not alter during this interval. Each of these eight patients had $T_{11}: T_{S / C}$ ratios of $<0.8$. Their original diseases consisted of hypertension, glomerulonephritis, hemolytic uremic syndrome, lupus erythematosis, and polycystic kidneys.

$\sharp$ Mean daily dosage of Medrol $\pm \mathrm{SE}$ as in $\bullet$. Each of these 13 patients had $\mathrm{T}_{11}: \mathrm{T}_{\mathrm{S} / \text { : }}$ ratios of $>0.8$. Their original diseases consisted of obstruction, focal segmental glomerulosclerosis, IgA nephropathy, diabetes, glomerulonephritis, amyloidosis, and medullary cystic disease.

of the patients after transplantation with $\mathrm{T}_{\mathrm{H}}: \mathrm{T}_{\mathrm{S} / \mathrm{C}}$ ratios of $>0.8$ in whom a positive response was found. The AMLR was absent in one patient with active systemic lupus erythematosus with antinuclear antibody titers of 1:4,000 who was uremic and on prednisone therapy in a dosage of $>20 \mathrm{mg} / \mathrm{d}$.

Inhibition of the AMLR by a naturally occurring $T$ cell of peripheral blood. In 22/23 normal individuals studied, we observed that the AMLR could be inhibited by addition of $x$-irradiated autologous $T$ cells, i.e. T + NTx was inhibited by addition of equal amounts of $T x$ cells. In preliminary experiments we used increasing concentrations of either Tx or NTx as the third component in the AMLR reaction. The inhibition could not be attributed to dilutional effects or cell numbers of responding vs. stimulating cells. If NTx (third component) were added at either one-half or two times the concentration routinely used (i.e. $1 \times 10^{5}$ cells) the magnitude of the AMLR was changed by $<20 \%$. However, addition of equivalent concentrations of $T x$ cells significantly affected AMLR inhibition (data not shown). The putative inhibitory third component population was added in equal numbers to the stimulating and responding cells for each experiment tabulated here. In Fig. 2 is shown the effect of Tx cells on the autologous $\mathrm{T}+\mathrm{NTx}$ reactions. The inhibition of the T + NTx was $\sim 90 \%$ after the addition of Tx cells $(P<0.01)$. This T cell AMLR inhibition was also active in $6 / 6$ patients tested who were on chronic maintenance hemodialysis in the absence of immunosuppression. In contrast to this finding, when a similar Tx cell inhibitor of the AMLR was looked for in PBL of kidney transplant recipients no such AMLR inhibitory effect was found. This absence of AMLR inhibitory cells was consistent regardless of the $T_{H}: T_{S / C}$ ratio or of the magnitude of response seen in the AMLR in 13/13 transplant patients with a positive AMLR. One exception, however, was seen in the negative AMLR group (patient G.W., vide infra).

Effect of isolation of $T_{H}$ and $T_{S / C} T$ cell subsets from the AMLR T cell inhibitor population. Since we had shown that $\mathrm{x}$-irradiated $\mathrm{T}$ cells of normal subjects suppressed the AMLR and that there was a general absence of such a suppressive effect in transplant recipients independent of the $T_{H}: T_{S / C}$ ratios in these patients, we asked whether such a "natural" AMLR 


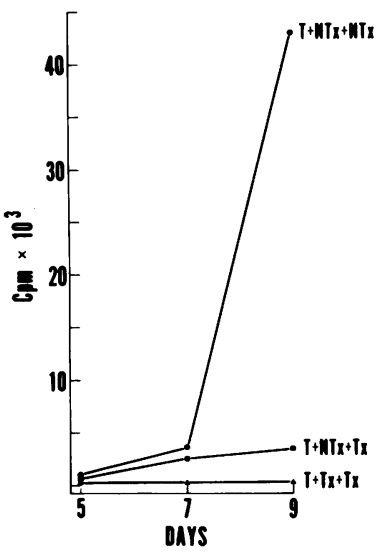

Figure 2 Inhibition of the AMLR by $T$ cells derived from peripheral blood lymphocytes. (1 of 23 subjects tested of which 22 were similar). These AMLR cultures were from normal individuals containing $1 \times 10^{5}$ each of responder $\mathrm{T}$ cells $(T)$ and $x$-irradiated (1,500 rad) non- $T$ stimulator cells (NTx) in complete medium. The putative suppressor cells $T$ were $x$-irradiated (3000 rad), and $0.1 \mathrm{ml}$ containing $1 \times 10^{5} \mathrm{Tx}$ or NTx cells were added as third components. Each point represents a mean of triplicates with $<10 \%$ variance, so that $T+N T x+T x$ is significantly different from $\mathrm{T}+\mathrm{NTx}+\mathrm{NTx}$ at a $P$ value of $<0.01$.

T cell inhibitory population was also independent of in vitro-derived $T_{H}$ and $T_{S / C}$ phenotypes isolated from PBL of normal individuals. We therefore separated the $E$ rosette-purified $T$ cells into $T_{H}$ and $T_{S / C}$ subsets by affinity column chromatography (Fig. 1). The effect of these $T$ cell subsets added as $\mathrm{X}$-irradiated third components in the AMLR is shown in Fig. 3. The same degree of inhibition was achieved for $T_{x}, T_{H x}$, and $T_{S / C x}$ subpopulations. Since the suppressor cell activity of the MLR is generally thought to occur in the $T_{s / C}$ population (21) it might have been reasoned that enrichment of this population, i.e., $>95 \% \mathrm{~T}_{\mathrm{s} / \mathrm{C}}$ would show an increase in AMLR inhibition, but it did not. Moreover, the suppression caused by the $\mathrm{T}_{\mathrm{Hx}}$ population that contained $<0.5 \% \mathrm{~T}_{\mathrm{S} / \mathrm{C} x}$ was similar to that produced by the unfractionated $T x$ or $T_{S / C x}$ subset. By contrast, we have previously described that $T_{H}$ and $T_{S / C}$ cells separated by the same affinity column technique, when added to the allogeneic MLR as third component caused amplification and suppression respectively (11). This suggests that AMLR inhibition was affected by a $T$ cell subset that crossed the $T_{H}$ and $\mathrm{T}_{\mathrm{S} / \mathrm{C}}$ phenotype boundaries.

Effects of naturally occurring $T$ inhibitory cells on the AMLR in HLA identical donor-recipient pairs. We then asked whether $T$ cells from normal donors would suppress the AMLR of HLA, A, B, C, D/DR identical kidney transplant recipients, and conversely, would recipient $\mathrm{x}$-irradiated $\mathrm{T}$ cells inhibit the donor's

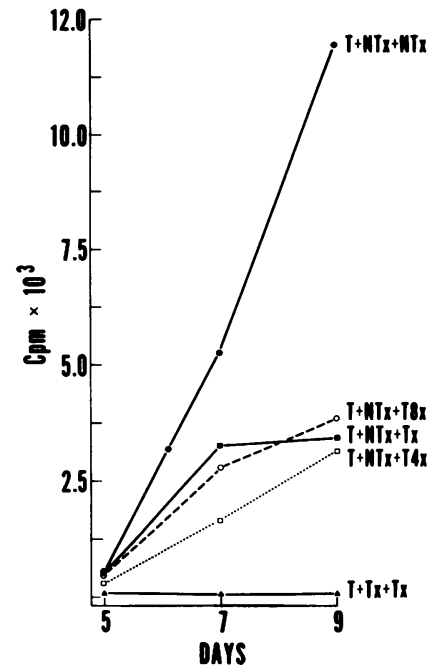

Figure 3 Effect of normal PBL $T_{11}$ and $T_{S / C}$ subsets purified by column chromatography (Fig. 1 ) after $E$ rosetting. The AMLR cultures were prepared from the same donor as the $\mathrm{T}_{11}$ and $\mathrm{T}_{\mathrm{S} / \mathrm{C}}$ subsets. $\left(\mathrm{T} 4=\mathrm{T}_{11} ; \mathrm{T} 8=\mathrm{T}_{\mathrm{S} / \mathrm{C}}\right)$.

AMLR. By exchanging the cells between subjects identical at the major histocompatibility complex, the effects of allogeneic stimulation or inhibition would be excluded. We studied four HLA identical donor-recipient pairs after transplantation. The results (recipients F.F., M.W., D.T., and G.W.) are presented in Table II. As seen in the previous experiment, the AMLR of the normal donor was inhibited by the addition of $x$-irradiated autologous $T$ cells, i.e., the DT + DNTx + DTx reaction was inhibited by at least $50 \%$ when compared with the DT + DNTx +; DNTx reaction $(P<0.01)$. The recipient $T$ cells $(\mathrm{RTx})$ failed to suppress the donor AMLR in three combinations studied (F.F., M.W., and D.T.). This was seen when DT + DNTx + DTX reaction was compared with DT + DNTx + RTx reaction. In two recipients (M.W. and D.T.) the AMLR was strong enough to be conversely tested with the addition of DTx cells, and an inhibitory effect was seen (RTx + RNTx + DTx vs. RTx + RNx + RTx $(P>0.01)$. Recipient F.F. had a low AMLR reaction at the outset, and although DTx inhibition was thought to be present (RTx + RNTx + DTx vs. RTx + RNTx + RTx) it was not as easily assessed (668 vs. $1,076 \mathrm{cpm}$ ). As a negative control, mixing DT + RTx caused no additional $\left[{ }^{3} \mathrm{H}\right]$ thymidine uptake over DT + DTx in culture and vice versa (not shown). In the fourth combination, G.W., the recipient AMLR reactivity was not present. This patient was on the most minimal dosage of daily immunosuppression in the series (Medrol $0.05 \mathrm{mg} / \mathrm{kg}$ and azathioprine 0.3 $\mathrm{mg} / \mathrm{kg}$ ), and showed the only dissociation seen in this 
TABLE II

Inhibition of the AMLR by Tx Cells of Normal Donors vs. Tx Cells of Immunosuppressed HLA Identical Recipients

\begin{tabular}{|c|c|c|}
\hline & Cell combination & $\begin{array}{l}\text { [3HThymidine } \\
\text { uptake }\end{array}$ \\
\hline & & $9 d$ in culture ${ }^{\circ}$ \\
\hline \multirow{6}{*}{$\begin{array}{l}\text { Pair 1, recipient } \\
\text { F.F. }\end{array}$} & $\mathrm{DT}+\mathrm{DNT}$ + DNTx & 16,507 \\
\hline & $\mathrm{DT}+\mathrm{DNTx}+\mathrm{DT} \mathrm{x}$ & $4,600 \ddagger$ \\
\hline & $\mathrm{DT}+\mathrm{DNT} x+\mathrm{RT} x$ & 14,010 \\
\hline & $R T+R N T x+R N T x$ & 1,076 \\
\hline & $\mathrm{RT}+\mathrm{RNTx}+\mathrm{RT} \mathrm{x}$ & 1,080 \\
\hline & $R T+R N T x+D T x$ & 668 \\
\hline \multirow{6}{*}{$\begin{array}{l}\text { Pair 2, recipient } \\
\text { M.W. }\end{array}$} & $\mathrm{DT}+\mathrm{DNTx}+\mathrm{DNTx}$ & 14,507 \\
\hline & $\mathrm{DT}+\mathrm{DNT} x+\mathrm{DT} x$ & $2,003 \ddagger$ \\
\hline & $\mathrm{DT}+\mathrm{DNTx}+\mathrm{RT} x$ & 10,761 \\
\hline & RT + RNTx + RNTx & 22,785 \\
\hline & $\mathrm{RT}+\mathrm{RNT}+\mathrm{RT} \mathbf{x}$ & 19,329 \\
\hline & $R T+R N T x+D T x$ & $7,135 \ddagger$ \\
\hline \multirow{6}{*}{$\begin{array}{l}\text { Pair 3, recipient } \\
\text { D.T. }\end{array}$} & DTx + DNTx + DNTx & 7,569 \\
\hline & $\mathrm{DT}+\mathrm{DNTx}+\mathrm{DT} \mathrm{x}$ & $1,642 \downarrow$ \\
\hline & $\mathrm{DT}+\mathrm{DNTx}+\mathrm{RTx}$ & 7,888 \\
\hline & $\mathrm{RT}+\mathrm{RNTx}+\mathrm{RNT} \mathrm{x}$ & 3,101 \\
\hline & $R T+R N T x+R T x$ & 3,515 \\
\hline & $\mathrm{RT}+\mathrm{RNTx}+\mathrm{DTx}$ & $694 \ddagger$ \\
\hline \multirow{6}{*}{$\begin{array}{l}\text { Pair 4, recipient } \\
\text { G.W. }\end{array}$} & $\mathrm{DT}+\mathrm{DNT} x+\mathrm{DNT} x$ & 7,398 \\
\hline & $\mathrm{DT}+\mathrm{DNT} x+\mathrm{DT} x$ & $3,213 \ddagger$ \\
\hline & DT + DNTx + RTx & $1,680 \ddagger$ \\
\hline & $R T+R N T x+R N T x$ & 839 \\
\hline & $R T+R N T x+R T x$ & 579 \\
\hline & $\mathrm{RT}+\mathrm{RNTx}+\mathrm{DT} x$ & $393 \$$ \\
\hline \multirow{3}{*}{$\begin{array}{l}\text { Pair 5, recipient } \\
\text { B.L. }\end{array}$} & DT + DNTx + DNTx & 17,000 \\
\hline & $\mathrm{DT}+\mathrm{DNT}+\mathrm{DT} x$ & $3,826 !$ \\
\hline & DT + DNTx + RTx & 14,046 \\
\hline
\end{tabular}

- Expressed as mean of triplicate cultures with $<10 \%$ variance. 5and 7-d cultures did not differ significantly from each other within the experimental groups of each pair except for trends becoming significant at day 9 .

I Greater than $50 \%$ inhibition was considered suppression. ( $P$ $<0.01$ ).

$\$$ This recipient two-component AMLR was nonresponsive. Therefore inhibition by DTX cells could not be assessed.

study between the presence of an RTx inhibitor of the AMLR, which could be demonstrated using the HLA identical donor responding cells (DT + DNT + RTX), and the absence of the AMLR in the recipient; the latter was more consistently dependent on the low $T_{H}: T_{S / C}$ ratio (0.19 in this patient). This exceptional observation, in a marginally immunosuppressed transplant recipient of the presence of Tx AMLR inhibitor cells in the absence of an AMLR, fortuitously seen because of the HLA identical cell interchange, again points to the independence of the $\mathrm{Tx}$ inhibitor to the $T_{H}: T_{S / C}$ ratio in vivo as pointed out in the preceding experiment using column-purified $T$ cell subsets in vitro.

As an additional study using this three component assay and cell interchange an HLA A, B, C, D/Dr identical sibling pair (pair 5, B.L., Table II) was studied before transplantation. The potential recipient was a 15-yr-old white male with "pseudo-Goodpasture's disease", i.e., hematuria and interstitial pulmonary hemorrhage, recurring episodically as he developed renal failure with biopsy proven glomerulonephritis in the absence of antiglomerular basement membrane antibody. His serum was $99 \%$ cytotoxic against a panel of 35 diverse HLA specificities, probably secondary ' to multiple transfusions, but negative when tested against an HLA identical sibling. At several intervals in his pretransplant course he was demonstrated to have autoantibodies (IgG) to his own T and B cells. He was treated with cyclophosphamide and prednisone. In the absence of continous antigenic stimulation of an allograft we asked what the effects of immunosuppression and/or autoimmunity might be on the presence of AMLR inhibitory T-cells in this patient. When the prospective donor DTx cells were added to DT + DNTx a strong inhibitory effect was seen (Table II). This was in contrast to the absence of inhibition seen with the addition of RTx to DT + DNTx.

Inhibition of the AMLR and allogeneic MLR by allogeneic vs. autologous primed $T$ cells. We have previously demonstrated the in vitro generation of allogeneic MLR primed human T suppressor cells that, when $x$-irradiated, suppressed the allogeneic MLR both specifically and nonspecifically (12). It has also been reported that two distinct cell populations appeared to be active in the AMLR and the allogeneic MLR (22), and that the AMLR has been associated with the generation of suppressor cells (9). We therefore asked whether $T$ cells primed in the AMLR and then $x$-irradiated would suppress either the AMLR or the allogeneic MLR and we compared this effect with Tx cells that had been primed in the allogeneic MLR. In these studies alloreactive primed cells from subject " A", a normal laboratory volunteer, and autologous primed cells of the same subject were generated by mixing A + Ix cells or AT + NTx, respectively, for 9 $d$ in culture. The $A^{\prime} I$ cell population produced at this time interval in the allogeneic MLR was purified by the $\mathrm{E}$ rosetting procedure to yield $\mathrm{AT}$ cells primed to Ix, (A'IT). The AMLR primed cells were similarly obtained ( $\left.T^{\prime} N T\right)$. The kinetics of the secondary allogeneic MLR and AMLR are compared with the primary AMLR in the Fig. 4A. The effects of these $x$-irradiated primed allogeneic MLR A'ITx compared with AMLR 

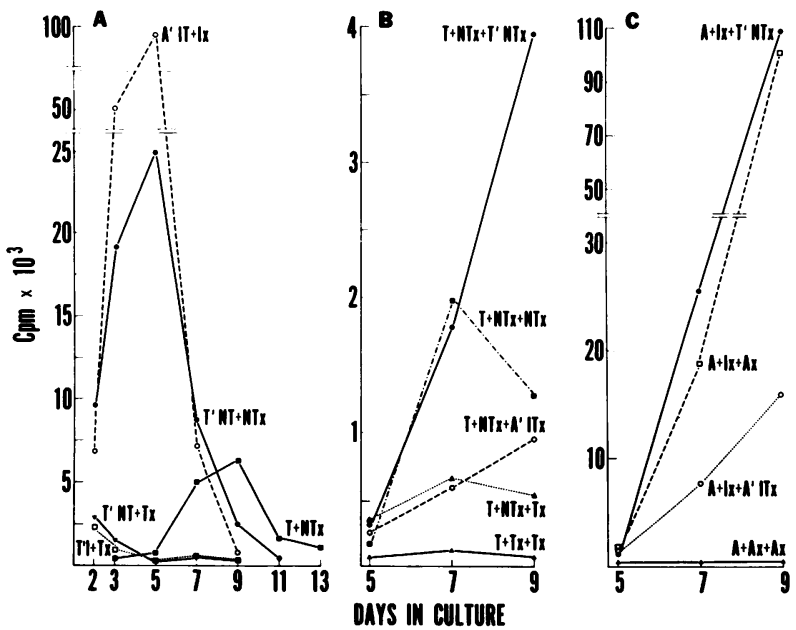

Figure 4 (A) The kinetics of the primary AMLR, secondary allogeneic MLR and secondary AMLR. Purified T cells were cultured with $\mathrm{x}$-irradiated autologous NTx cells for $3,5,7$, 9,11 , and $13 \mathrm{~d}$ for the primary AMLR. The secondary allogeneic culture was performed by first obtaining cells from a primary MLR $\mathrm{A}+\mathrm{Ix}=\mathrm{A}^{\prime} \mathrm{I}$ at $\mathbf{9} \mathrm{d}$ culture. The secondary autologous culture was similarly derived from a primary $T+N T x$ culture that yielded primed $T^{\prime} N T$ cells after $9 \mathrm{~d}$ of culture. The cultured cells were washed and resuspended in fresh medium at a concentration of $10^{6}$ viable cells $/ \mathrm{ml}$ and rechallenged with freshly prepared $x$-irradiated NTx cells $\left(2^{\circ} \mathrm{C}\right.$ AMLR $)$ or $x$-irradiated Ix cells $\left(2^{\circ} \mathrm{C}\right.$ allogeneic MLR). These $2{ }^{\circ} \mathrm{C}$ cultures were maintained for $2-9 \mathrm{~d}$, with thymidine incorporation measured during the last $16 \mathrm{~h}$ of culture. The mean $\left[{ }^{3} \mathrm{H}\right]$ thymidine incorporation for triplicate values are plotted for each point. (B) The effect of A'ITx, $T^{\prime} N T x$ and $T x$ added as third components to the AMLR $(T+N T x)$. Equal numbers of responders, stimulators and primed cells $\left(1 \times 10^{5}\right)$ were cultured for $5,7,9 \mathrm{~d}$. (C). The effect of $A^{\prime} I T x, T^{\prime} N T x$ and $A x$ on the allogeneic MLR $(A+I x)$

$\mathrm{T}^{\prime} \mathrm{NTx}$ cells added as third components to the AMLR are shown in Fig. 4B. The autologous primed $\mathrm{T}$ cell ( $\mathrm{T}^{\prime} \mathrm{NT} \mathrm{x}$ ) did not inhibit the AMLR (in contrast to the naturally occurring freshly prepared $\mathrm{Tx}$ from PBL described in the previous experiment [Fig. 2]). However, the A'ITx inhibitory effect was similar to Tx obtained from PBL in the ability to suppress the AMLR. Also in the converse experiment, when x-irradiated allo-and auto-primed cells were added as third components to the allogeneic MLR A'ITx caused suppression (as previously described $[12,17]$ ) but $\mathrm{T}^{\prime} \mathrm{NTx}$ did not (Fig. 4C).

\section{DISCUSSION}

The AMLR in normal subjects has not been clearly equated to any well defined immunological function, although the concept of a regulatory role in immune homeostasis has been proposed $(1,2)$. There may still be the reservation that it is an in vitro artifact, since mixing autologous $\mathrm{T}$ and non-T cells at $1 \times 10^{6} / \mathrm{ml}$ in culture is quite different from the densities at which such cells occur in vivo in peripheral blood. Kozak et al. (6) performed limiting dilution analysis on the AMLR to estimate the number of autoreactive $T$ cells. If calculations are made using those data, assuming that the ratio of stimulating to responding cells required in vitro is also needed in vivo, the AMLR would not be measurable in peripheral blood (and indeed is not). It has also been estimated that the level of corticosteroids in blood might well be sufficient to suppress the in vivo AMLR (3). Therefore, the occurrence of a measurable AMLR in vivo would require a compartmentilization or anatomical juxtaposition in fixed lymphoid tissue of the cells involved. This is rather different from the allogeneic MLR that we and others have measured using lymphocytes extracted from the infiltrated allograft $(23,24)$. Notwithstanding, if the assumption is made that there is a biologic function of the AMLR, then the AMLR itself should require regulatory controls. In our search for these, we attempted to generate auto- and alloprimed $\mathrm{T}$ suppressor cells. (Fig. 4A, B, C). In previous reports $(12,17)$ we have shown that both specific and nonspecific primed $T$ suppressor cells can be generated in allogeneic MLR. In the present study autoprimed $\mathrm{T}^{\prime} \mathrm{NT} x$ failed to suppress the AMLR and had no effect on the proliferative response of fresh T cells to allogeneic cells in the MLR. However, the allogeneic MLR primed cells suppressed both allo and autoreactive $T$ cells. The observation that AMLR activated T cells were not suppressive in allogeneic MRL is in contrast to the data of Smith and Knowlton (25) and MacDermott and Stacey (10). In both of those reports, however, nonirradiated cells were used and the kinetics of the reactions were not detailed. The clear demonstration of a cellular suppressive effect occurring in immune reactions in vitro is difficult when primed cells are used in the absence of attempts to inactivate their own proliferation response and to fully examine the early and late kinetics of the reaction, as in the present study.

In our experiments, an AMLR inhibitory cell that exhibits the OKT4 phenotype cannot be ruled out, since nonprimed $\mathrm{T}$ cells obtained from peripheral blood and $x$-irradiated were found to cause inhibition of the AMLR in normal human subjects, regardless of $\mathrm{T}_{\mathrm{H}}$ or $\mathrm{T}_{\mathrm{S} / \mathrm{C}}$ purification by in vitro methods. This inhibitory cell was also seen in several uremic patients untreated with immunosuppression with normal $T_{H}: T_{S / C}$ ratios. The evidence adduced indicates that this suppressive action was not related to $T_{H}$ or $T_{S / C}$ phenotypes nor was it artifactual, i.e., related to chang- 
ing cell concentrations in the three-component reaction. In several preliminary experiments using twofold dilutions of either Tx or NTx cells as the third component in the cultures, encompassing the cell concentrations used in the present experiments, increasing or decreasing NTx caused essentially no effect while changing the $T x$ cell concentration markedly altered AMLR activity. More to the point, however, with one exception (G.W., Table II), none of the transplant patients tested who were immunosuppressed with corticosteroids and either azathioprine, cyclophosphamide, or cyclosporin A demonstrated the presence of these circulating $\mathrm{T}$ cells that inhibited the AMLR. (The presence of AMLR Tx inhibitor cells in G.W. is postulated to be due to the extremely low daily dose of immunosuppression required in the patient [Medrol $0.05 \mathrm{mg} / \mathrm{kg}$, azathioprine $0.3 \mathrm{mg} / \mathrm{kg}$ ] due to marked sensitivity of the $T$ cell subset ratio $\left[T_{H}: T_{S / C}=0.19\right]$ even at this dose. This patient had had a prolonged aspergillus infection that resolved after pulmonary lobectomy and amphotericin B treatment as well as virtual discontinuance of immunosuppression therapy for 4 mo.) Quite possibly a different membrane marker might be present on these Tx natural AMLR inhibitory cells such as the Fc-IgG receptor T gamma cell, which is suppressive in various systems and which demonstrates $>90 \%$ ERFC with OKT4 and OKT8 markers in roughly equal distribution (26-28).

It has been proposed that the AMLR has a potential autoregulatory function in vivo by generating suppressor cells $(9,10)$. In the present study, the paradoxical absence of a "natural" AMLR inhibitory $\mathrm{T}$ cell in the peripheral blood of immunosuppressed patients adds credence to this hypothesis. Immunosuppression would teleologically suppress the inhibitor of the autoregulator, i.e. result in a net suppressive effect consistent with a network hypothesis (29-31).

We have previously reported that immunologic monitoring of transplant recipients produced benefits in two areas; in the nonspecific assessment of altered generalized resistance to opportunistic infections (primarily a $\mathrm{T}$ cell dependent function) and in the demonstration of specific regulatory activity toward alloantigens of the graft $(16,32,33)$. We began a study of the AMLR in transplant recipients because as an in vitro assay it appeared to have exquisite sensitivity, albeit nonspecific, to factors that alter immunity. This was in contrast to our previous immunological monitoring studies in which immunosuppressive therapy given in moderate dosage had no major effect on either the allogeneic MLR, the blastogenic response, nonspecific $\mathbf{T}$ cell cytotoxicity or antibody-dependent cellmediated cytotoxicity reactions. By monitoring the $\mathrm{T}_{\mathrm{H}}: \mathrm{T}_{\mathrm{S} / \mathrm{C}}$ subset ratios, however, we did find significant inversions $(17,18)$ when patients were highly susceptible to infection even when only minimal dosages of immunosuppressive therapy were administered. If a gradation in sensitivity of these in vitro assays to the effects of immunosuppression were to be proposed, since $T_{H}: T_{S / C}$ ratios and AMLR assays were not affected (i.e. normal) but the Tx AMLR inhibitor cell was no longer present in all but one (G.W.) of the transplant recipients studied, this latter cell would be a candidate to be the most sensitive to the effects of immunosuppressive therapy. Following in descending order, the AMLR on a level with $T_{H}: T_{S / C}$ ratios appears to be the next most sensitive assay to be affected. The allogeneic MLR and the generation of cytotoxic T cells in this reaction (not shown), although perhaps more dependent on genetic disparity as well, are less sensitive. The latter assays were in general present independent of the $T_{H}: T_{S / C}$ ratios, and only appear to be affected when the total $T$ cell $E$ rosette population is depleted by prolonged high doses of such therapy (16).

\section{ACKNOWLEDGMENT}

This work was supported in part by National Institutes of Health grant 5R01 AM 25243-06 and by Veterans Administration research support.

\section{REFERENCES}

1. Opelz, G., M. Kiuchi, M. Takasugi, and P. Terasaki. 1975. Autologous stimulation of human lymphocyte subpopulations. J. Exp. Med. 142: 1327-1333.

2. Kuntz, M. M., J. B. Innes, and M. E. Weksler. 1976 Lymphocyte transformation induced by autologous cells. IV. Human T lymphocyte proliferation induced by autologous or allogeneic non-T lymphocytes. J. Exp. Med. 143: 1042-1054.

3. Hahn, B. H., R. P. MacDermott, S. Barkholde Jacobs, L. S. Pletscha, and M. G. Beale. 1980. Immunosuppressive effects of low doses of glucocorticoid: Effects on autologous and allogeneic mixed leukocyte reactions. $J$. Immunol. 124: 2812-2817.

4. Sakane, T., A. D. Steinberg, and I. Green. 1978. Failure of the autologous mixed lymphocyte reaction between $T$ and non-T cells in patients with systemic lupus erythematosus. Proc. Natl. Acad. Sci. USA. 75: 3464-3468.

5. Kuntz, M. M., J. B. Innes, and M. E. Weksler. 1979. The cellular basis of the impaired autologous mixed lymphocyte reaction in patients with systemic lupus erythematosus. J. Clin. Invest. 63: 151-153.

6. Kozak, R. W., C. E, Moody, L. Staiano-Coico, and M. E. Weksler. 1982. Lymphocyte transformation induced by autologous cells. XII Quantitative qualitative differences between human autologous and allogeneic reactive T lymphocytes. 128: 1723-1727.

7. Weksler, M. E., and Robert Kozak. 1977. Lymphocyte transformation induced by autologous cells. V. Generation of immunologic memory and specificity during the autologous mixed lymphocyte reaction. J. Exp. Med. 146: 1833-1838. 
8. Kyuhei, T. 1980. Cytotoxic $\mathrm{T}$ cells generated in the autologous mixed lymphocyte reaction. I. Primary autologous mixed lymphocyte reaction. J. Immunol. 124: 1111-1121.

9. Sakane, T., and I. Green. 1979. Specificity and suppressor function of human $T$ cells responsive to autologous non-T cells. J. Immunol. 123: 584-589.

10. MacDermott, R. P., and M. C. Stacey. 1981. Further characterization of the human autologous mixed leukocyte reaction (MLR). J. Immunol. 126: 729-733.

11. Flaa, C., L. Fuller, G. K. Kyriakides, and J. Miller. 1982. The functional significance of T4-T8 $\mathrm{T}$ cell subsets in kidney transplantation. Fed. Proc. 41: 937.

12. Fuller, L., G. Kyriakides, C. Flaa, V. Esquenazi, and J. Miller. 1980. In vitro generation of human mixed lymphocyte culture suppressor cells I. Cellular characterization and specificity. Transplantation (Baltimore). 29: 54-59.

13. Evans, R. L., H. Lazarus, A. C. Penta, and S. F. Schlossman. 1978. Two functionally distinct subpopulations of human $T$ cells that collaborate in the generation of cytotoxic cells responsible for cell-mediated lympholysis. J. Immunol. 120: 1423-1428.

14. Solliday, S., and F. H. Bach. 1970. Cytotoxicity specificity after in vitro sensitization. Science (Wash. DC) 170: 1406-1408.

15. Miller, J., C. Clark, and C. Flaa. 1979. In vitro generation of suppressor cells in human mixed leukocyte culture: a potential treatment modality in organ transplantation. Transplant. Proc. 11: 899-903.

16. Miller, J., J. Lifton, W. C. Dewolf, B. J. Stevens, and C. Wilcox. 1977. The efficacy of immunological monitoring after renal transplantation. Transplant. Proc. 9: 59-64.

17. Severyn, W., G. K. Kyriakides, L. Fuller, V. Esquenazi, C. Flaa, L. Olson, C. Goldsmith, and J. Miller. 1981. Kidney transplantation using splenectomy and transfusion, cadaver haplotype matching, suppressor cell assays and T cell monitoring. Surgery (St. Louis). 90: 364-375.

18. Kyriakides, G. K., L. Olson, C. Flaa, W. Severyn, V. Esquenazi, and J. Miller. 1982. The effect of HLA haplotype, DR and MLR matching on cadaveric renal transplant survival. Surgery (St. Louis). 92: 354-361.

19. Severyn, W., C. Flaa, L. Fuller, G. K. Kyriakides, V. Esquenazi, and J. Miller 1982. The role of immunological monitoring in transplantation. Heart Transplant. 1: 222-229.

20. Snedecor, G. W., and W. G. Cochran. 1967. Statistical Methods. Iowa State University Press, Ames, IA. 6th ed. 59-60.

21. Reinherz, E. L., P. C. Kung, C. Goldstein, and S. F. Schlossman. 1980. A monoclonal antibody reactive with the human cytotoxic/suppressor $\mathrm{T}$ cell subset previously defined by a heteroantiserum termed $\mathrm{TH}_{2}$. J. Immunol. 124: 1301-1307.

22. Fournier, C., and J. Charreire. 1982. Autologous mixed lymphocyte reaction in man. II. Autoreactive and alloreactive cells belong to two different $\mathrm{T}$ cell subsets. $J$. Immunol. 128: 2698-2703.

23. Hattler, B. G., J. Miller, and M. C. Johnson. 1972. Cellular and humoral factors governing canine mixed lymphocyte culture after renal transplantation. II. Cellular. Transplantation (Baltimore). 14: 47-56.

24. Strom, T. B., N. L. Tilney, C. B. Carpenter, and G. J. Busch. 1975. Identity and cytotoxic capacity of cells infiltrating renal allografts. N. Engl. J. Med. 292: 12571263.

25. Smith, J. B., and R. P. Knowlton. 1979. Activation of suppressor $\mathrm{T}$ cells in human autologous mixed lymphocyte culture. J. Immunol. 123: 419-422.

26. O’Malley, J. A., A. Nussbaum-Blumenson, D. Sheedy, B. J. Grossmayer, and H. Ozer. 1982. Identification of the $\mathrm{T}$ cell subset that produced human interferon. $J$. Immunol. 128: 2522-2526.

27. Kadish, A. S., F. A. Tansey, G. S. M. Yu, A. T. Doyle, and B. R. Bloom. 1980. Interferon as a mediator of human lymphocyte suppression. J. Exp. Med. 151: 637650.

28. Moretta, L. S., R. Webb, C. E. Grassi, P. M. Lydyard, and M. D. Cooper, 1977. Functional analysis of two human $T$ cell subpopulations: help and suppression of $B$ cell response by $T$ cells bearing receptors for $\operatorname{IgM}(\mathrm{T} \mu)$ and IgG (Tr). J. Exp. Med. 146: 184-200.

29. Gershon, R. K., D. D. Eardley, S. Duram, D. R. Green F. W, Shen, K. Yamauchi, H. Cantor, and D. B. Murphy. 1981. A novel immunoregulatory activity. J. Exp. Med. 153: $1533-1546$.

30. Jerne, N. K. 1974. Toward a network theory of the immune system. Ann. Immunol. 125c: 373-389.

31. Urbain, J., C. Wuilmart, P. A. Cazenare Franssen, B. Mariane, and O. Leo. 1981. Idiotypic regulation in immune networks. Contemp. Top. Mol. Immunol. 8: 113148.

32. Hattler, B. G., C. Karesh, and J. Miller. 1971. Inhibition of the mixed lymphocyte culture responses by antibody following successful human renal transplantation. Tissue Ant. 1: 270-275.

33. Miller, J., J. Lifton, F. Rood, and B. G. Hattler. 1975 Blocking versus cytotoxic antibody in HLA and mixed lymphocyte culture-identical and nonidentical human renal transplant recipients. Transplantation (Baltimore). 20: 53-62. 